\title{
"I felt they were ganging up on me": Interviewing siblings at home
}

\author{
Samantha Punch \\ Department of Applied Social Science \\ University of Stirling \\ Stirling \\ FK9 4LA
}

Email: s.v.punch@stir.ac.uk

\begin{abstract}
The paper explores the methodological implications and some of the intergenerational and intra-generational power relations involved when carrying out research with children at home. It draws on data from individual and group interviews about children's experiences of sibling relationships and birth order. The study was conducted with 90 children between the ages of 5 and 17, from 30 families of mixed socio-economic backgrounds in central Scotland with three siblings within this age range. The paper discusses some task-based interview techniques as well as the advantages and disadvantages of interviewing siblings individually and in groups within the home setting.
\end{abstract}

Paper published in:

Punch, S. (2007) "I Felt they were Ganging up on me”: Interviewing Siblings at Home, Children's Geographies, 5(3): 219-234. 


\section{"I felt they were ganging up on me": Interviewing siblings at home}

Since the 1990s there has been an overwhelming increase in the number of studies conducting research with children which has led to many discussions of appropriate ways to engage children in the research process (for example, Fraser et al., 2004; Lewis et al., 2004). In particular there has been a focus on ethics (Alderson and Morrow, 2004; Hill, 2005) and the extent to which doing research with children is the same or different to doing research with adults (Lewis and Lindsay, 2000; Punch, 2002a). It is now widely acknowledged that, as children have different competencies and interests, there is no one magic method to carrying out research with them (Boyden and Ennew, 1997; Christensen and James 2000). Thus, some studies recommend a flexible multi-method approach (Clark, 2004; Punch, 2001) or the use of multiple techniques within one key method, such as employing a range of tools during interviewing (Hadfield and Edwards, 2005; Morrow, 1998; Punch, 2002b).

This paper contributes to the growing field of researching with children by discussing the implications of interviewing siblings in their family home. The paper begins by comparing what participants saw as the benefits and limitations of using both group and individual interviews. It explores the inter-generational and intra-generational power relations involved in doing research with children in the home context. Both the temporal and spatial aspects of interviewing children in the domestic arena are considered. Finally, the paper discusses the use of task-based interview tools in enabling the children to express their understandings of sibling relationships. Throughout the paper, there will be some reflection on the extent to which the issues raised are particular to research with children or are potentially relevant to research with any social group.

\section{Background to the study}

Most research on sibship has been conducted from a psychological perspective focusing primarily on the ways in which sibling relationships and birth order impact upon the developmental stages of childhood (for example Dunn, 1984; Lamb and Sutton-Smith, 1982). In contrast using a more sociological and geographical approach to studying sibship enables a more contextualised exploration of processes of sibling interaction and negotiation. More recently within the social studies of childhood, some research has begun to explore children's own perceptions of their sibling relationships (Brannen et al., 2000; Edwards et al., 2005a; 2005b; McNamee, 1997; Morrow, 1998) and this paper contributes to this growing field of research.

The paper is based on a Scottish study of children's experiences of sibship and birth order, conducted as part of a British Academy post-doctoral fellowship. The research explores the ways in which children understand sibling relationships and how the negotiation of sibling roles varies according to birth order, age and gender (Punch, 2005). The study considers the extent to which children draw on siblings as a source of support both within and outside the family. It also investigates the ways in which children consider siblings to be a source of problems (both rivalry and conflict) and how they negotiate outcomes to such tensions (McIntosh and Punch, forthcoming). 
The study began with an exploratory phase of essay-based classroom research at three Scottish schools where 180 children (aged 7-14) wrote essays about their experiences of sibling relationships. This stage informed the design of semi-structured interviews and enabled access to be negotiated with a sample of 30 families with three children between the ages of 5 and 17. Each of the 90 siblings were interviewed individually in their homes, followed by 30 focus group interviews with all three siblings together. The children were all full siblings of mixed socio-economic backgrounds, mostly living with both of their biological parents except for three single mother households. Thus the sample was formed to explore the impact of birth order and sibship in families with three children.

In order to obtain anonymous feedback regarding children's perceptions of their involvement in the study, I used a 'secret box' (see Punch, 2002b) at the end of the second interview. I asked them to tick boxes at the top of the paper to indicate their sex and birth order position so I could compare responses according to these variables. I encouraged them to find their own space in the room to fill out the sheet individually and anonymously, folding it up afterwards and posting it into a small hole at the top of a box which was otherwise completely sealed with sellotape. I explained that I would only open up the box once all the research was finished. This assured them that their responses would be anonymous and they could write whatever they wanted about their experiences of taking part in the study (see also Edwards and Alldred, 1999). I hoped that this would allow them to write any negative comments which they may have been restrained from expressing if the evaluation was just returned to me in person and thus not quite so anonymous.

I only began this evaluation-in-the-box technique after conducting interviews with six families, thus I obtained 70 responses from 24 families. The total included 40 boys (13 oldest, 13 middle and 14 youngest children) and 30 girls (11 oldest, 11 middle and 8 youngest children). Some of the data presented in this paper is thus based on the children's own anonymous reflections of taking part in the research. In order to distinguish between the different participants, I use a ' $B$ ' or ' $G$ ' to indicate boy or girl respectively, and an ' $\mathrm{O}$ ', ' $\mathrm{M}$ ' or ' $\mathrm{Y}$ ' to differentiate between oldest, middle and youngest siblings. Thus ' $G M$ ' refers to a middle girl sibling. When quotations from the interviews are used, I use a pseudonym to protect the child's identity, followed by their age, birth order and number of family interviewed.

\section{Comparing group and individual interviews}

On the evaluation sheet the children were asked which type of interview they preferred taking part in. Overall they marginally preferred the group interviews compared with the individual interviews (39 compared to 29), as can be seen in Figure 1: 
Figure 1: Boys and girls preferences of group or individual interviews according to birth order

\begin{tabular}{|l|c|c|c|c|}
\hline & $\begin{array}{c}\text { Group } \\
\text { interview }\end{array}$ & $\begin{array}{c}\text { Individual } \\
\text { interview }\end{array}$ & $\begin{array}{c}\text { No } \\
\text { response }\end{array}$ & Total \\
\hline Boy - oldest & 5 & 8 & - & 13 \\
\hline Boys - middle & 8 & 4 & 1 & 13 \\
\hline Boys - youngest & 8 & 5 & 1 & 14 \\
\hline Total boys: & 21 & 17 & 2 & 40 \\
\hline Girls - oldest & 8 & 3 & - & 11 \\
\hline Girls - middle & 5 & 6 & - & 11 \\
\hline Girls - youngest & 5 & 3 & - & 8 \\
\hline Total girls: & 18 & 12 & - & 30 \\
\hline Total & $\mathbf{3 9}$ & $\mathbf{2 9}$ & $\mathbf{2}$ & $\mathbf{7 0}$ \\
\hline
\end{tabular}

Just over half of the girls and boys across the birth order positions preferred the group interviews, except for the oldest boys (5 for groups compared to 8 for individual interviews) and the middle girls (5 for groups compared to 6 for individual interviews). However, given that the numbers are relatively small no major conclusions can be drawn apart from noting that groups are slightly the preferred option, but also many children preferred the individual interview so there is not a clear ideal as to which type of interview is perceived to be more suitable (see also Punch, 2002b).

A range of reasons for preferring each kind of interview were given. The main reason stated for preferring the individual interview was because it enabled them to speak freely: "Because I could say what I want and I had more to say" (GO). There were several explanations for why the individual interview facilitated greater freedom of expression (see also Valentine, 1999a). First, because it was more private:

\footnotetext{
You could say things you couldn't exactly say with the group (GO)

I got to say things that I couldn't tell family about (GO)

Easier to say things about your siblings (BO)

Could say things and not feel bad (BO)
}

Secondly, the focus was just on them: "You got to speak more and answer yourself" (GM) and there were no interruptions: "I didn't have two sisters interrupting and being brats" (BO) and "You didn't have anyone butting in" (GM). Thirdly, there were no arguments to deal with: "No argument, say whatever you want” (BO). Finally, two children in the youngest birth order position highlighted that the individual interview avoided any impacts from unequal power relations between the siblings:

I felt they were ganging up on me (GY)

Mainly cause people never made fun of me cause nobody was here (BY)

It was specifically decided to arrange the group interviews to follow the individual interviews so that any unequal power relationships between the siblings would not influence the research agenda for the individual interviews. The above comments indicate that this was perhaps a rational decision. Another unanticipated reason for having the group interviews after the individual ones, was because some children 
indicated to me that they had been anxious as to what their siblings would be saying about them during the individual interview. The subsequent group interview thus provided them with an opportunity to hear for themselves what their siblings thought of them:

I enjoyed the group discussion because we let each other know what we think (BY)

Because you could hear your brothers things (BY)

Because everyone got to hear what you were saying (GY)

You could hear what the others had to say about me (BM)

The anxiety and/or curiosity about what the other siblings had discussed with me, is not unique to children's experiences of being interviewed separately in family homes. Valentine notes that adult couples may worry that they might be judged or are anxious 'because each cannot manage the impression of themselves being reproduced by the other' (1999a: 71). Being interviewed together enables household members, whether children or adults, to negotiate the production of their shared accounts. In the siblings study, hearing each other's views was one of the key reasons given for preferring the group interview whether this just confirmed what they already knew or not:

I preferred the group interview because we all heard about what each other thought even though we knew most of it anyway (GY)

You know what they feel about you (GO)

Because you learnt what your brothers think of you (BO)

Whilst, for some, the individual interview had been easier as they could speak more freely, several children felt that the group interview was easier for different reasons. There was slightly less pressure in the group situation, "Didn't have to think all yourself" (GM), as ideas could be shared and sparked off each other (see also Lewis, 1992; Punch 2002b):

\footnotetext{
Because your siblings help you to brain storm (GO)

Because it had the input of three people (GO)

I could expand on what the others were saying or think of what to say from what they said (GO)

I preferred the group interview because it was easy to think of things to say (GM)
}

Some of the main advantages of group interviews with participants of any social group are the spontaneity of the discussion (Krueger, 1994), the jogging of each other's memories (Valentine, 1999a) and the more relaxed and fun atmosphere (Stewart and Shamdasani, 1990). However, these benefits can be particularly suitable for children who are possibly (but not necessarily) more likely to perceive the interview situation as a somewhat daunting experience (Bushin, this volume), as they are perhaps less likely to be used to communicating at length with unfamiliar adults (Punch, 2002a). This was reflected in some of the children's responses to participating in the siblings' research. Some felt the group interview was easier because it was: "more relaxed" (GO) and they were not by themselves: "because I had others with me" (BY), "my brothers were there" (BM) and "because we had company" (GM). Furthermore, it was perhaps less nerve-wracking for some as it was the second interview:

It was easier to talk and I wasn't so nervous because I knew what to expect (GO) 
Thus to some extent the group interview was perceived to be more fun, partly because of the banter with their siblings and feeling more relaxed in their company and partly because more group activities could be attempted:

It was more fun things and when I did it on my own we didn't do as much things sometimes just drawing things (BY)

The group interviews also allowed for more discussion: "Because I liked it when my brothers and sisters were there to agree and disagree" (GY), even though sometimes this resulted in arguments. As one boy pointed out: "it allowed me to show what I talked about in the single interview actually happening" (BO). One of the aims of the group interview had been to allow for some sibling interaction to be observed and as the previous quote and the next section shows, to some extent this was possible. However, the downside to this was that it was difficult to trying to cater for siblings of mixed ages and competencies (see also Hennessy and Heary, 2005).

\section{Managing sibling group interviews}

In particular the power struggles between the different birth order positions meant that for me the group interview proved to be quite challenging at times. For example, sometimes the older and middle siblings dominated the discussions perhaps because of their wider range of vocabulary and greater linguistic experience of the world (Boyden and Ennew, 1997). It was not always easy for me to bring the youngest sibling into the conversation as even my direct questions to them were sometimes answered by one of the older siblings:

Sam: And when he gets annoyed what do you do Andy?

BY: Errr....

BO: You just go in a big hump and he just starts shouting things down the stairs "I should get to stay up late!". (George 11, Andy 5, Family 23)

As a result of having others speak for them, the youngest sibling sometimes reacted in specific ways such as by not answering questions at all (see also Bushin, this volume) or by shouting or by speaking in a high-pitched voice. To some extent this reflects a common problem of group interviews as some members of the group can dominate and the researcher should aim to encourage the quieter individuals to contribute their views (Bloor et al., 2001; Krueger, 1994). However, this can pose a particular problem when the group interviews are based on the pre-existing social group of family members. For example, parents may try to take control and speak for their children (Bushin, this volume; Valentine, 1999b) or one half of a couple may constantly interrupt and speak for their partner (Valentine, 1999a). Similarly, some of the sibling group interviews dissolved into all the children speaking at once or arguing, and usually it was the oldest who would try to end a dispute:

GY: This is what he does, he goes... (imitating it).

[talking over each other - Jackie and Marcos demonstrating fighting by rolling around on top of each other on the floor and shouting]

SAM: We won't be able to hear anything!

BM: Jackie! Get off! Get off me! 
[Marcos really screeching]

GO: Jackie get off him. Stop it! Jackie stop acting smart. Stop it you two. You stop it. (Josephine 15, Marcos 9, Jackie 5, Family 5)

Thus at times my research coincided with the 'ethical minefield' that Valentine described in her study with British parents: 'What starts out as light-hearted banter between a couple over a disputed event or activity can rapidly deteriorate into a fullblown conflict, with the interviewer caught in the crossfire' (1999a: 70). As a child researcher, I found it difficult to know how best to cope with the more explosive group situations because the 'researcher' part of me wanted to observe the sibling interactions, but the 'adult' part of me felt that perhaps I should do something. Bloor et al. argue that:

Where groups are composed of members drawn from pre-existing social groups, it is both inevitable and desirable that the group interactions in the focus group reflect the group interactions in the pre-existing group: one group member may be more forceful than others, another may be the group humorist, and so on. Of course, the facilitator should not seek to overturn these natural features of group interaction. (Bloor et al., 2001: 50)

However, ethically this is difficult when it involves children and actual or potential physical fighting, particularly amongst siblings who are likely to experience power struggles, including physical force and overt resistance (Punch, 2005). I tried to compromise with partial involvement by pointing out that the tape would not be able to pick up what they are saying if they were arguing. However, when some arguments progressed or fighting began, it was difficult to decide how I should respond (see also Morris-Roberts, 2001). I did not want to appear like the typical adult, telling them to what to do or trying to discipline them (see also Hennessy and Heary, 2005). I was also curious as to how they might resolve the situation themselves, yet I felt that their parents would perhaps expect me to retain some control if fights broke out. I had to be prepared to intervene on occasions as I did not want them to hurt each other or for the interview to end in tears. It was not an easy dilemma to resolve, and I tried to respond to each particular situation as it occurred. I usually waited to see how they might deal with the incident themselves and, if the situation deteriorated, I tried appealing to their better nature by asking them not to continue arguing or fighting or by attempting to regain their interest in a particular task. These kinds of interactions did enable me to observe some sibling power struggles being played out in practice (Punch, 2005). However, it was difficult to balance ethical concerns with the social research view that 'the focus group is meant to be tapping into group life, not changing it' (Bloor et al., 2001: 50).

Morris-Roberts (2001) calls for children's geographers to engage with a feminist 'politics of intervention' where researchers challenge oppressive behaviour and encourage research participants to reflect on their practices. In relation to this siblings' research, my main reason for intervening was related to issues of child safety but there are also ethical and moral responsibilities surrounding the reinforcement of negative sibling behaviour based on gender, age and birth order. In particular I felt caught between the interests of the research in terms of watching sibling relationships unravel without intervention and the ethics involved in not questioning unequal gendered and intra-generational power imbalances. In practice there are multiple difficulties in trying to resolve these kind of conflicts which arise during the research 
process, and the researcher is often left feeling uncomfortable because of the ethical ambiguities which they face (see also Morris-Roberts, 2001; Valentine, 1999b).

It is worth considering that all group interviews are likely to be affected to some degree by the perceived power or status of different members of the group (Stewart and Shamdasani, 1990), whether that is derived from age, gender, class, education or any other social variable. Dealing with power dynamics and conflict amongst the group is a common aspect of managing group interviews (Krueger, 1994) and is not just relevant to children. However, given that birth order, particularly during childhood, is linked to hierarchical notions of power and authority (Edwards et al., 2005a) which can be contested, resisted and negotiated (McIntosh and Punch, forthcoming), power struggles during sibling group interviews are likely to be fairly frequent, and at times quite intense, as in this study. For example, on many occasions siblings seemed to take delight in contradicting each other as a matter of course often even before they considered whether the other actually had a valid point or not:

SAM: What would happen?

BO: Dawn would agree to what I say and Ann would stomp away in a huff.

GM: No I wouldn't

BO: Yes you would Ann!

GM: Okay yes I would. (Ray 10, Ann 8, Family 24)

I also witnessed sibling alliances evolving when two siblings (usually either both oldest or both youngest rather than the oldest and youngest together) appeared to be 'ganging up on' the other:

BM: Duncan! It's an interview!

Sam: It's okay

BO: Duncan you're being asked a question, you know?

BY: Yes I know.

BO: Duncan what are you doing! ...

BM: Duncan you are just blaming everybody. This is an interview. It's not an insultation competition! [all talking at once] ...

BM: What's that say? (referring to something Duncan has written on the paper for a writing task)

BO: Duncan, you're just wasting space

BM: You've wasted half the paper! (Michael 10, Christian 8, Duncan 6, Family 29)

Therefore, the group interviews gave greater insights into the nature of sibling interactions as their conversations and their behaviour reflected both the conflictual as well as the supportive elements of their sibships. The groups provided evidence of the ways in which siblings can switch rapidly between positive and negative behaviour towards each other (Punch, forthcoming). Whilst group interviews generally enable both nonverbal and verbal aspects of group interaction to be observed and recorded (Stewart and Shamdasani, 1990), the observation of group dynamics can be particularly interesting when the participants are members of the same household (see also Bushin, this volume; Valentine, 1999a). During childhood, sibship is often characterised by arguments and fights as well as care and concern (Edwards et al., 2005b; Punch 2005). Hence, the fluctuating nature of this relationship can result in sibling group interviews being a challenging yet illuminating research encounter. Thus, whilst generating useful and interesting data which indicated the ambivalent 
nature of sibling power relations, the group interviews were also more difficult to manage and clearly hear all of what was being said (see Hoppe et al., 1995).

It is also worth bearing in mind that, for some children, sibling conflicts are an 'integral part of their feelings of connection to their siblings' (Edwards, et al. 2005a: 45) whereas for others they could be much more problematic. To some extent, this might explain why some of the sibling group interviews worked really well and others did not gel so well. However, this can happen in any research as some groups can be more difficult to conduct (Hennessy and Heary, 2005; Krueger, 1994). In the siblings study, it was partly dependent on the mixed ages of the siblings and the ways in which they interacted with each other, and partly because of my impact on the group dynamic. Whilst the self-selected sample of siblings in my research were not likely to be experiencing extreme levels of violence and conflict as they volunteered from the outset to take part in both group and individual interviews, it is acknowledged that it might not always be appropriate to conduct group interviews with siblings in all contexts.

\section{The home setting}

It is important to consider the impact that conducting interviews at home can have on family interactions when the researcher is not present. It emerged several times that the interviews were talked about and sometimes used in sibling power struggles as these following quotes indicate:

She just annoys me. Like today, she was like: 'I'm going to tell Samantha Punch about you' (mimicking a whiney voice). (Gareth 13, oldest, Family 26)

Sam: How do you think she'd describe you as a brother?

BM: She probably would say 'annoying' and 'horrible'. She said that she's going to say horrible things about me [when you interview her] (Graham 11, middle child, Family 4)

It was apparent that before or after the interviews some siblings teased each other with what they might say or have said about them. Sometimes I worried that the research might have a negative impact on their sibships. Protecting research subjects from harm is not a specific ethical issue that only applies to working with children, as most researchers frequently worry about the appropriateness of their behaviour in the field, particularly their: 'methodology, personality and morality' (Devereux 1992: 43). Ethically it is the researcher's responsibility not to make any interviewee feel worse after an interview. However, in the siblings' study it was not realistic to think that the interview process would encourage siblings to argue or annoy each other less than they usually do. Perhaps, as some of them suggested in their evaluations, their involvement in the research may have enabled them to be more reflexive about their sibships and think about their birth order positions from different perspectives: "I thought that the project made me think about aspects of sibship I hadn't thought about before" (BO). Nevertheless, aspects of their relationships such as conflict, rivalry and support would continue to be key features of their interactions (Punch, 2005). Consequently to some extent I feel reassured that if siblings used their participation in the research as a way of bartering or negotiating with their brothers and sisters outwith the interview situation, this was not unlike other forms of sibling interactions (see Edwards et al. 2005b; McIntosh and Punch, forthcoming). 
It is also worth taking into account that the home interviews might be affected to some extent by the nature of sibling interactions immediately prior to the interview. For example, as the following quotes suggest, the context of the interview is important because if the siblings had just had an argument, perhaps they might be more willing to be negative in some of their responses:

Sam: How might he describe you as a brother?

BO: Oh, I don't want to think about it. I suppose if you asked him at different times he'd have different opinions. Like if I'd annoyed him in the recent past then he'd use it. (Robert 16, oldest, Family 18)

I always like them but it's just a certain scale - how much I like them on the day. (Graham 11, middle child, Family 4)

Whilst to some extent this is particularly pertinent for the sibling relationship which tends to be characteristised as a fluctuating relationship, moving swiftly between positive and negative experiences (Punch, forthcoming), nonetheless, these methodological issues are relevant to all types of interviewing. We have to bear in mind that 'an interview is a social encounter like any other' (May, 1997: 129) so the kind of data we collect depends on many factors including the research setting, the context in which the interview takes place, and the extent to which the interviewer has managed to build rapport and a relationship of trust with the interviewee (Westcott and Littleton, 2005). One of the limitations of using interviews with anyone, not just children, is that we have to rely on people's views as told in the interview situation. This is a key reason why it was beneficial in this research to conduct both individual and group interviews, as the group situation allowed for individual viewpoints to be validated, questioned or challenged (see also Valentine, 1999a), highlighting the contested and negotiated nature of much sibship interaction. Meanwhile the individual interview enabled siblings to talk at length and in detail about their own understandings of sibship without interruptions or tensions emerging from the group context. Consequently it is argued that using both individual and group interviews, with either children or adults, enables researchers to combine the benefits of each type of interview.

When conducting interviews at home, it is also important to consider that children are likely to talk about their experiences of being interviewed with other family members. At the start of the interviews, I made it clear to the children that if they wanted to discuss what we talked about to their parents or siblings, that was their choice. My main aim was to reassure them that I certainly would not be discussing anything they told me with either their parents or their siblings. I had to take care to ensure I did not slip up on this promise in any way as it could be difficult at times when parents asked me very direct questions afterwards (see also Valentine, 1999b). Some parents were very curious to know whether their children's fighting was perceived by me as 'normal'. I tried to give very non-committal, vague answers but this can be hard when they know you have just been talking to their children in-depth (see also Bushin, this volume). Sometimes I would have to gently remind them that I could not break their children's confidentiality, but again this is not necessarily an easy thing to tell a parent who is perhaps concerned about what we may have discussed. To some extent this affects the kind of families which volunteer to take part in such research. Families that have siblings who are particularly violent towards each other or are dealing with 
specific problems might not have been willing to volunteer to let a stranger into their homes to interview their children. Thus it is important that I recognise the limitations of this self-selecting sample.

Nevertheless, it is always worth considering in advance what steps might be taken if a child did disclose abuse, no matter how unlikely it may seem. Researchers should always decide before fieldwork begins whether they can offer full or partial confidentiality to their participants, and this is particularly pertinent for research with children (see Alderson and Morrow, 2004). For example, in this siblings' project I told the child participants that the interview would be totally confidential, taking the risk that if some form of abuse or harm was disclosed I would have to discuss that with the child concerned, knowing that I might have to breach that confidentiality if they insisted on secrecy. In practice, no such situation emerged. However, in a previous study on young people's problems (Hallett et al., 2003), because of the potentially more sensitive nature of the topic, I began the interview by offering partial confidentiality. This meant I told the young people that if they indicated that their life was in danger, as an adult, I would have a moral responsibility to do something about that, but I would discuss possible action with them first. Child researchers should consider the issue of disclosure and confidentiality carefully before embarking on their fieldwork, but the decision of whether to announce partial or full confidentiality should depend on the research topic, the sample of children and the research context.

Another practical and geographical aspect of conducting research within the home is that it is important to recognise that the research setting may affect the subject matter of the data generated (Hennessy and Heary, 2005). For example, in previous research on young people's problems carried out with 13-14 year olds in schools (Hallett et al., 2003), many of the examples given spontaneously were from the school context and, in order to explore how they coped with problems at home, I specifically had to ask about this different arena. Similarly, in the family setting, most siblings talked about their everyday lives within the home together. I tended only to get data on the nature of their sibships at school or outside the home when I specifically asked for it. Thus the content of children's (or adults') accounts is likely to be affected by the environment in which they are sought. The impact of the research setting is a general issue to consider in any research and is not just relevant to researching with children.

The geographical location of the research context is not only important regarding whether interviews are conducted at home or at school, but may even be affected by the choice of room within the home. For example, children may feel more relaxed in their own bedroom space surrounded by their own belongings. Particular possessions or toys may provide illustrations for discussion of sibling interactions. As a researcher I preferred being able to conduct the interview more informally on children's bedroom floors rather than being seated more formally at a dining room table. This was because it tended to take slightly longer to develop rapport and encourage children to relax in the more adult-centred living rooms. I also liked the opportunity to see the kind of spaces where children would frequently interact with their siblings. For example, during one individual interview, the middle sibling indicated how she and her sister divided their shared bedroom into two bounded spaces which marked their own territory which the other sibling was supposed to respect. Similarly, toys could be drawn into the discussion as evidence of sibling disputes over personal possessions or as an ice-breaker chat at the start of the interview. 
However, this is a controversial issue primarily for reasons of child protection (Hazel, 1996; McDowell, 2001). The safety of both the child participants and the adult researcher need to be considered carefully. Anyone conducting research with children should have a police check and in Scotland there is now a legal requirement for enhanced 'Disclosure Scotland' checks to be undertaken by child researchers. Some researchers may disapprove of interviews being conducted in children's bedrooms (McDowell, 2001) and the gender matching of interviewer and interviewee is likely to be relevant. Hazel argues that when doing research in schools, 'researchers should try to find a room for interviews which provides a reasonable degree of audible privacy, but where physical activity is visible to others' (1996: 2). Hoppe et al. (1995) also suggest that children should be interviewed in a public place, but when interviewing in children's own homes, the space is already private and, in order to retain confidentiality, it has to be where others cannot overhear the discussions. Thus at home, almost any room will be out of sight and not public.

Furthermore, as I have argued elsewhere, adult researchers should not always assume that children will feel most comfortable with an unfamiliar adult in their own childhood space (Punch, 2002a). It should also be recognised that children do not always have autonomy over their bedroom space and conducting interviews there may result in reinforcing the lack of control they have over privacy and space in the home. Consequently, where possible I tried to let children decide where they preferred the interview to take place, but in practice parents had often decided beforehand. On reflection this is something which should have been discussed and negotiated when organising the time and date of the interviews. In many cases, by the time I arrived on the actual day, it could be difficult to renegotiate a parental decision that had already been made, especially when the room and use of household space had been organised accordingly. The room for the interview was also determined by the size of the family home and the presence of other family members. Sometimes the child's bedroom was the only available space which enabled the interview to be confidential (see also Valentine, 1999b).

Ideally it should be the children's decision as to which space they feel most at ease in talking about a particular topic with an adult researcher. However, both children and parents have to be comfortable with where the interview is to be conducted. Thus, as Bushin (this volume) also found, it is important to be flexible regarding the specific location and manner in which interviews in family homes may be conducted. Afterwards the researcher should reflect on the extent to which the particular room and setting may have shaped not only the interview content but also the rapport built up between the interviewee and themselves (Robinson and Kellett, 2004).

\section{Task-based interview tools}

Before conducting the research, I assumed that the subject matter would be relatively easy for children to talk about and, to a certain extent, I was right. Most children had little difficulty in discussing what they liked and disliked about having brothers or sisters. However, sometimes the familiar is too familiar and when I asked for specific examples to illustrate a particular issue, it was not always easy for the respondent to think of one relatively quickly: 
Well, erm, I can’t really think of any, but it does really happen. I just can’t think of any. (George 11, oldest, Family 23)

Just like, I don't know, it's kind of hard to give examples, but it just is. (Steven 15, oldest, Family 3)

My response was to reassure them that it was okay, recognising that I knew I was putting them on the spot by asking them to come up with specific examples which was not always easy. This is by no means specific to research with children as respondents of any age may find it difficult to provide spontaneous examples to illustrate particular issues which emerge during the course of an interview. It also partly explains why some children in this study found the group interview easier as something one of the others said might spark off a memory of particular incidences (Lewis, 1992). It was not only difficult for some children to think of examples of their sibship interactions but some also found it hard to express the ambivalence of their love/hate relationships:

I get on sometimes with both of them, sometimes without... it's really hard to explain (Barry 9, middle child, Family10)

It's hard to explain really, I can’t put words to it. (Giles 14, oldest, Family 22)

Consequently, it was useful to introduce some task-based activities into both the group and individual interviews in order to facilitate the communication of ideas (Boyden and Ennew, 1997; Punch, 2002b). The main tools used were spider diagrams, charts, lists and ranking exercises. Again, it should be emphasised that interview activities were not only incorporated because the research participants were children, as they can also be effective with adults, such as vignettes (Finch, 1987) and photographs (Hurworth, 2003). There is a tendency perhaps for child researchers to create and develop such tools more extensively for use with children, but perhaps it could be argued that flexible, creative ways to enhance communication in a variety of forms should also be considered more frequently with adult research participants.

As I had a keen interest in birth order, in the individual interview I asked questions about which position they might prefer to be in. Many children were quick to point out that this was actually a difficult question to answer given that they have never experienced the other birth order positions:

I think I like being the oldest, I just can't picture it any other way really but yeah I enjoy being the oldest. (Steven 15, oldest, Family 3)

That's pretty impossible... because you've never been the oldest and you've never been the youngest. If you had 24 hours being each it would be easier. I quite like being the middle one 'cos I don't know about the other two. (Christian 8, middle child, Family 29)

This is perhaps why many of the children enjoyed hearing their siblings views in the group interview as it enabled them to reflect upon their different experiences. Previously I have found that one of the most effective group tasks for brainstorming is the use of spider diagrams (see Punch 2002b). Consequently I used them at the 
beginning of the group interview because they could serve as a warm-up activity as well as a means for providing useful comparative data.

'The oldest' was written in a circle in the middle of a large sheet of paper and each sibling, with a different colour pen, added a leg to the spider diagram by writing different aspects of what it is or might be like to be the oldest sibling. This was a springboard for a more in-depth discussion of the advantages and disadvantages of being the oldest. Thus, the spider diagrams were used as a visual aid on which to build information and probe in more detail. Each child could actively take part and add to the diagram, by writing or drawing if they preferred. Spider diagrams were an effective way for children to define what they perceived as the central features of each birth order position.

A fairly open, brainstorming task was also used in the individual interview when children wrote all the good and bad things about having siblings on separate pieces of paper headed by smiling or sad faces. Subsequently they ranked their responses according to what they most and least liked about their siblings. The advantages of this task was that it allowed children time to think about which issues they would like to raise and they were not under pressure to respond immediately to a particular question. It also gave the children a chance to settle in to the interview and start thinking about siblings in a very open-ended way. They could define the issues that were most important to them in their sibling relationships, and these then directed the subsequent discussion.

Where possible I tried to use the interview tools in a flexible manner (see also Bushin, this volume; Hadfield et al., 2005). To some extent this depended on time taken to complete previous activities, the interview dynamic, the children's preferences and my ability as a researcher to have developed a good rapport with the participants. For example, in the individual interview I used a social network task where children wrote or drew themselves in the middle of a piece of paper and added all the people who are important to them. This visual representation was used to compare children's sibships with other important relationships in their lives, such as their friends or parents. Some children appeared at ease and confident with straightforward talking (Harden et al., 2000), whereas others seemed to prefer the visual task-based activities. However, to avoid making incorrect, possibly 'adultist' assumptions, I offered them the choice of whether they preferred to talk, write or draw about their social networks. Using tools in a slightly different manner helps to cater for children's varied preferences and skills as well as enabling children to feel more comfortable with an unfamiliar adult researcher (Punch, 2002a). The difficulty is that sometimes the data generated through different techniques is harder to compare across the interviews but, providing the main themes are consistently addressed, this usually is not a problem in qualitative interviewing.

\section{Conclusions: Conducting research at home with children}

This paper has explored the ethical and methodological issues involved in carrying out intra-generational group interviews and individual interviews with siblings in their homes. The implications go beyond the specificity of sibling relationships and may be of interest to anyone conducting qualitative interviews with children. In particular, the paper has highlighted the temporal and spatial aspects of interviewing in family 
homes, as well as some of the difficulties of addressing the tensions between the interests of the research and ethical concerns.

Undertaking research with siblings in the home setting raises a range of issues before, during and after the interviews take place (see also Bushin, this volume). The child participants, the parent gatekeepers and the adult researcher should all feel comfortable about when and where the interviews are conducted as this shapes the nature of the data generated. It has to be recognised that both inter-generational and intra-generational power relationships will need to be considered and negotiated when interviewing children at home. Furthermore, it should not always be assumed that the home is an appropriate context for interviewing children, as for some it may not be a safe, protective space and this may lead to a certain degree of bias in a self-selecting sample of participants when stipulating that the research setting will be their family home.

This paper concurs with other studies that argue that when researching with children it is often appropriate to use a mixture of methods and techniques in order to engage their interest and enable them to express their views in a flexible manner (Boyden and Ennew, 1997; Greene and Hogan, 2005). In particular, using task-based activities in both the individual and group interviews is an attempt to minimise unequal power relations between the adult researcher and child participants (Punch, 2002b; Robinson and Kellett, 2004). However, it is important that the researcher critically reflects on the advantages and disadvantages of using different types of interviews and techniques.

It is interesting to note that most of the methodological and ethical issues considered in this paper are also relevant to research with adults. But do we go to such creative lengths when researching with adults to be flexible and offer a range of choices regarding their preferred forms of communication? Perhaps, if we do not, we should? Thus, it could be argued that doing research with children possibly encourages researchers to engage more intensely with certain aspects of the research process because of the more obvious structural inequalities in the way that childhood is socially constructed in British society (Punch, 2002a). However, perhaps we are in danger of overlooking some of these issues with adults which results in our tendency to stick to more traditional interview approaches. More extensive and creative planning and preparation of fieldwork may be just as beneficial in research with adults. For example, studies with adults are also likely to benefit from a range of interview tools as well as combining both group and individual interviews. Using both types of interview enables researchers to observe group dynamics and explore power relations within the group, whilst also engaging in more private, in-depth discussions with individuals on a one-to-one basis.

Whilst this paper has argued that combining both group and individual interviews is beneficial for several reasons, it may not always be feasible in practice, particularly in relation to the time and money available for any project. Researchers should also carefully consider the sequencing of conducting focus groups before individual interviews or vice-versa. It may not always be appropriate to use both types of interview as it will also depend on the research context, topic and sample of participants. However, as we have seen in the siblings' study, it can be advantageous to interview research participants both together and apart. On the one hand, focus 
groups provide a useful opportunity to observe sibship interactions in practice and to develop group discussions. On the other hand, it can be difficult to manage the power relations played out amongst siblings of different ages and birth order positions in one group interview. Thus it is worth remembering that the type of interview, the particular techniques used, the geographical location and the research context each have benefits and limitations attached to them. As researchers, we need to be aware of what these are so that we can minimise the difficulties and maximise their effectiveness.

\section{Acknowledgements}

In particular, I would like to thank all the children and young people who took part in this siblings' research. Grateful acknowledgement to the British Academy for their financial support of this study. I would also like to thank Mike Kesby and the anonymous referees for their helpful comments in redrafting this paper.

\section{References}

Alderson, P. and Morrow, V. (2004) Ethics, Social Research and Consulting with Children and Young People, Ilford: Barnardo’s.

Bloor, M., Frankland, J., Thomas, M. and Robson, K. (2001) Focus Groups in Social Research, London: Sage.

Boyden, J. and Ennew, J. (1997) (eds) Children in Focus: A Manual for Experiential Learning in Participatory Research with Children, Stockholm: Rädda Barnen.

Brannen, , J., Heptinstall, E. and Bhopal, K. (2000) Connecting Children: Care and Family Life in Later Childhood, London: Routledge Falmer.

Clark, A. (2004) The Mosaic Approach and Research with Young Children, in: Lewis, V., Kellet, M., Robinson, C., Fraser, S. and Ding, S. (eds) The Reality of Research with Children and Young People, London: Sage, 142-161.

Devereux, S. (1992) 'Observers are Worried': Learning the Language and Counting the People in Northest Ghana,' in Devereux, S. and Hoddinott, J. (eds) Fieldwork in Developing Countries, London: Harvester Wheatsheaf.

Dunn, J. (1984) Sisters and Brothers, London: Fontana.

Edwards, R., Hadfield, L. and Mauthner, M. (2005) Children's Understanding of their Sibling Relationships, London: National Children’s Bureau.

Edwards, R., Mauthner, M. and Hadfield, L. (2005a) Children's Sibling Relationships and Gendered Practices: Talk, activity and deadling with change, Gender and Education 17 (5): 499-513.

Edwards, R. and Alldred, P. (1999) Children and Young People's Views of Social Research: The case of research on home-school relations, Childhood 6 (2): 261-281.

Finch, J. (1987) The Vignette Technique in Survey Research, Sociology 21 (1):25-34. 
Fraser, S., Lewis, V., Ding, S., Kellet, M. and Robinson, C. (eds) (2004) Doing Research with Children and Young People, London: Sage.

Greene, S. and Hogan, D. (eds) (2005) Researching Children's Experience: Approaches and Methods, London: Sage.

Hadfield, L., Edwards, R. and Mauthner, M. (2005) Resources for Investigating Children's Experiences and Perspectives: Sibling Relationships in Middle Childhood, Families and Social Capital, http://www.lsbu.ac.uk/families/jrfsibresources

Hallett, C., Murray, C., and Punch, S. (2003) Young People and Welfare: Negotiating Pathways, in: Hallett, C. and Prout A. (eds) Hearing the Voices of Children: Social Policy for a New Century, London: RoutledgeFalmer, 123-138.

Harden, J., Scott, S., Backett-Milburn, K. and Jackson, S. (2000) Can’t Talk, Won’t Talk?: Methodological Issues in Researching Children, Sociological Research Online 5 (2), http://www.socresonline.org.uk/5/2/harden.html.

Hazel, N. (1996) Elicitation Techniques with Young People, Social Research Update 12, Guildford: University of Surrey.

Hennessy, E. and Heary, C. (2005) Exploring Children's Views through Focus Groups, in: Greene, S. and Hogan, D. (eds) Researching Children's Experience: Approaches and Methods, London: Sage, 236-252.

Hill, M. (2005) Ethical Considerations in Researching Children's Experiences, in: Greene, S. and Hogan, D. (eds), Researching Children's Experience: Approaches and Methods, London: Sage, 61-86.

Hoppe, M., Wells, E., Morrison, D., Gillmore, M. and Wilsdon, A. (1995) Using Focus Groups to Discuss Sensitive Topics with Children, Evaluation Review, 19(1):102-114.

Hurworth, R. (2003) Photo-Interviewing for research, Social Research Update 40, Guildford: University of Surrey.

Krueger, R. (1994) Focus Groups: A Practical Guide for Applied Research, London: Sage.

Lewis, A. (1992) Group Child Interviews as a Research Tool, British Educational Research Journal, 18 (4): 413-421.

Lewis, V., Kellet, M., Robinson, C., Fraser, S. and Ding, S. (eds) (2004) The Reality of Research with Children and Young People, London: Sage.

Lamb, M. and B. Sutton-Smith (1982) Sibling Relationships: Their Nature and Significance Across the Lifespan, London: Lawrence Erlbaum.

Lewis, A. and G. Lindsay (eds) (2000) Researching Children's Perspectives. Buckingham: Open University Press.

May, T. (1997) Social Research: Issues, Methods and Process, Buckingham: Open University Press.

McDowell, L. (2001), 'It's that Linda again': Ethical, Practical and Political Issues involved in Longitudinal Research with Young Men, Ethics, Place and Environment, 4 (2): 87-100. 
McIntosh, I. and Punch, S. (Forthcoming) 'Barter', 'Deals', 'Bribes' and 'Threats': Exploring Sibling Interactions, Childhood.

McNamee, S. (1997) 'I won't let her in my room': Sibling Strategies of Power and Resistance around Computer and Video Games, in: Seymour, J. and Bagguley, P. (eds) Relating Intimacies: Power and Resistance, Basingstoke: Macmillan.

Morris-Roberts, K. (2001) Intervening in Friendship Exclusion? The Politics of Doing Feminist Research with Teenage Girls, Ethics, Place, and Environment, 4 (2): 147-153.

Morrow, V. (1998) Understanding Families: Children's Perspectives, London: National Children's Bureau.

Punch, S. (2001) Multiple Methods and Research Relations with Young People in Rural Bolivia, in: Limb, M. and Dwyer, C. (eds) Qualitative Methodologies for Geographers, London: Arnold, 165-180.

Punch, S. (2002a) Research with Children: The Same or Different from Research with Adults? Childhood, 9 (3): 321-341.

Punch, S. (2002b) Interviewing Strategies with Young People: The 'Secret Box', Stimulus Material and Task-based Activities, Children \& Society, 16: 45-56.

Punch, S. (2005) The Generationing of Power: A Comparison of Child-Parent and Sibling Relations in Scotland, Sociological Studies of Children and Youth, 10: 169-188.

Punch, S. (forthcoming) "You can do Nasty Things to your Brothers and Sisters Without a Reason”: Siblings’ Backstage Behaviour, Children \& Society.

Robinson, C. and Kellett, M. (2004) Power, in: Fraser, S., Lewis, V., Ding, S., Kellet, M. and Robinson, C. (eds) Doing Research with Children and Young People, London: Sage, 81-96.

Stewart, D and Shamdasani, P. (1990) Focus Groups: Theory and Practice, London: Sage.

Valentine, G. (1999a) Doing Household Research: Interviewing couples together and apart, Area, 31 (1): 67-74.

Valentine, G. (1999b) Being Seen and Heard? The Ethical Complexities of Working with Children and Young People at Home and at School, Ethics, Place and Environment, 2 (2): 141-155.

Westcott, H. and Littleton, K. (2005) Exploring Meaning in Interviews with Children, in: Greene, S. and Hogan, D. (eds) Researching Children's Experience: Approaches and Methods, London: Sage, 141-157. 